\title{
Structural resistance of orthodontic mini-screws inserted for extra- alveolar anchorage
}

\author{
Carlos A. M. Vieira' ', Francyelle Pires' ${ }^{1}$, Wallisen. T. Hattori², Cleudmar A. de Araújo³, Marcelo \\ A. Garcia-Junior', Darceny Zanetta-Barbosa' \\ 1. Universidade Federal de Uberlândia, Faculdade de Odontologia, Programa de Pós-Graduação em Odontologia, \\ Uberlândia, Brasil. \\ 2. Universidade Federal de Uberlândia, Faculdade de Medicina, Departamento de Saúde Coletiva, Uberlândia, Brasil. \\ 3. Universidade Federal de Uberlândia, Faculdade de Engenharia Mecânica, Departamento de Biomecânica, \\ Uberlândia, Brasil.
}

\begin{abstract}
The risk of fracture or strain in mini-screws is higher if diameter, length, type of alloy or insertion angle is selected inappropriately. The aims of this study were to test the structural resistance of two types of orthodontic mini-screws-one made of stainless steel and another of titanium-from an international brand and to evaluate the efficacy of two other titanium miniscrews of Brazilian origin, during an extra-alveolar anchorage procedure. The mini-screws analyzed were: Bomei stainless steel and Bomei titanium / Taiwan, Morelli titanium and Neodent titanium/ Brazil. Experiments were conducted on pig mandibles to simulate the process of extra-alveolar anchorage. Two insertion processes were used: Direct at $30^{\circ}$, and Indirect, starting at $60^{\circ}$ and ending at $30^{\circ}$ with gradual continuous movement. Strain was evaluated using Optical and Scanning Electron Microscopy. Data were evaluated using Kruskal-Wallis non-parametric statistical analysis and post hoc Tamhane test.
\end{abstract}

Significant statistical differences in strain were observed among the mini-screws used in the extra-alveolar insertions, both for the direct and indirect procedures. In the indirect insertion tests, both stainless steel and titanium mini-screws suffered deformation, showing that angling can be an important factor in mini-screw failure rates. The change in angle during the insertion movement increased deformation rates independently of alloy type, increasing the risk of failure. These results could help orthodontists in choosing mini-screws for extra-alveolar anchorage, which can be performed with direct or indirect insertion. In vivo studies should be conducted to confirm the findings of this study.

Received: October 2020; Accepted: January 2021.

Keywords: orthodontics - orthodontic anchorage techniques dentistry.

\section{Resistência estrutural de mini-aparafusos ortodônticos inseridos para ancoragem extra-alveolar}

\begin{abstract}
RESUMO
O risco de fratura ou tensão nos mini-parafusos é maior se o diâmetro, comprimento, tipo de liga ou ângulo de inserção for selecionado de forma inadequada. Os objetivos deste estudo foram testar a resistência estrutural de dois tipos de miniaparafusos ortodônticos -um feito de aço inoxidável e outro de titânio-de uma marca internacional e avaliar a eficácia de dois outros mini-parafusos de titânio de origem brasileira, durante um procedimento de ancoragem extra-alveolar. Os miniaparafusos analisados foram: Bomei aço inoxidável e Bomei titânio / Taiwan, Morelli titânio e Neodent titânio / Brasil. Foram realizadas experiências em mandibulas de porcos para simular o processo de ancoragem extra-alveolar. Foram utilizados dois processos de inserção (Direta a 30 e Indireta, começando a $60^{\circ}$ e terminando a $30^{\circ}$ com movimento gradual contínuo). A deformação foi avaliada utilizando Microscopia Óptica e Microscopia Eletrônica de Varredura. Os dados foram avaliados utilizando análise estatística não paramétrica
\end{abstract}

Kruskal-Wallis e teste post-hoc Tamhane. Diferenças estatísticas significativas na deformação foram observadas entre os miniparafusos utilizados nas inserções extra-alveolares, tanto para os procedimentos diretos como indiretos. Nos testes de inserção indireta, tanto os mini-parafusos de aço inoxidável como os de titânio sofreram deformação, mostrando que a angulação pode ser um fator importante nas taxas de falha dos mini-parafusos. A mudança no ângulo durante o movimento de inserção aumentou as taxas de deformação independentemente do tipo de liga, aumentando o risco de falha. Estes resultados podem ajudar os ortodontistas na escolha de mini-parafusos para ancoragem extra-alveolar, que pode ser realizada com inserção direta ou indireta. Estudos in vivo devem ser conduzidos para confirmar os resultados deste estudo.

Palavras-chave: ortodontia - técnicas de ancoragem ortodôntica-odontologia. 


\section{INTRODUCTION}

Skeletal anchorage has been widely used in orthodontics because it does not allow movement of the reaction unit, providing satisfactory results for anchorage control with less discomfort to the patient ${ }^{1}$. To be considered ideal, a skeletal anchorage system must have certain characteristics, such as easy installation, resistance to orthodontic forces, simple removal, small size, and being ready for early activation to minimize treatment time and maximize efficiency ${ }^{2}$.

According to the literature, among the means for achieving skeletal anchorage, the orthodontic miniscrew technique has shown the most significant clinical applicability compared to other skeletal anchorage systems such as integrated bone implants or mini-plates ${ }^{3}$.

Orthodontic mini-screws have distinct shapes and sizes. Most of them are manufactured in titanium alloy grade V (Ti-6Al-4V) specified by the ASTM F136 standard ${ }^{4}$. Skeletal anchorage can also be achieved using AISI 316L Austenitic stainless steel ${ }^{5}$ Skeletal anchorage can be interradicular or extraalveolar. In interradicular anchorage, mini-screw insertion requires positioning guides with local radiographs and correct root inclination. Direct insertion, on a site with low bone thickness, should be performed avoiding inclination movements ${ }^{6}$.

In extra-alveolar anchorage, mini-screws are inserted into a great bone thickness. Inclination and torsions movements are usually necessary to avoid contact with dental roots. Extra-alveolar anchorage has been widely used because it is efficient in the treatment of certain deformities, especially for retractions of the entire upper or lower dentoalveolar complex ${ }^{7}$. However, mini-screws must be used adequately, considering the loads involved and their mechanical properties and structural resistance ${ }^{8}$. It is therefore essential to know the magnitude of the torques involved, and local anatomical structures. Gingival tissue and bone density must be taken into account as factors that can influence the installation of anchorage 9 . Professional experience is important at the time of selecting and using mini-screws, to minimize mini-screw losses and iatrogenic injury. Dental surgeons still have doubts about which miniscrew system to use, due to the high use of titanium, mainly in extra-alveolar anchorage, which requires a significant level of torque and angulation to avoid root contact.
The aim of this study was to test the structural strength of mini-screws of different brands using an in vitro model. Pig mandibules were used to test the ability of mini-screws to withstand insertion/removal torques without suffering deformation or fracture during the extra-alveolar insertion procedure.

\section{MATERIALS AND METHODS}

Fourty orthodontic mini-screws with the same diameters and lengths were used: 20 made of stainless steel (OBS Bomei/Taiwan, $2.0 \mathrm{~mm}$ in length, $12 \mathrm{~mm}$ diameter (Gold standard) and 20 made of titanium OBS Bomei/Taiwan $(2.0 \times 12 \mathrm{~mm})$. We also tested another 40 titanium mini-screws of two popular Brazilian brands: 20 Morelli/Brazil (1.5 x $10 \mathrm{~mm})$ and 20 Neodent/Brazil $(1.6 \times 11 \mathrm{~mm})$, in the largest diameters and lengths available, but with smaller diameter and lengths than gold standard. We evaluate their capabilities in extra-alveolar inserts, since they are designed and manufactured for interradicular insertion. Fig. 1 shows the geometry of the tested mini-screws, and Table 1 shows the main characteristics of the mini-screws used in the extra-alveolar insertion tests.

\section{Experimental Setup for Extra-Alveolar Anchorage Tests}

Extra-alveolar anchorage was simulated in the region of the buccal shelf with great bone thickness in pig mandibles. The density and bone metabolism of pig mandible are similar to those of human bones ${ }^{10}$, which makes them compatible for in vitro analysis. Eighty fresh mandible semi-arches of adult pigs with approximate weight and size were obtained from a slaughterhouse (Frigorífico São Pedro-Uberlândia/ MG-Brasil). During the procedures the mandibles were stored in a refrigerator at $6^{\circ} \mathrm{C}$ to $10^{\circ} \mathrm{C}$.

A reference system (positioners made of 0.17 " $\mathrm{x}$ 0.25 " stainless steel wires) was used for positioning the angles $\left(30^{\circ}\right.$ and $\left.60^{\circ}\right)$ during the insertion

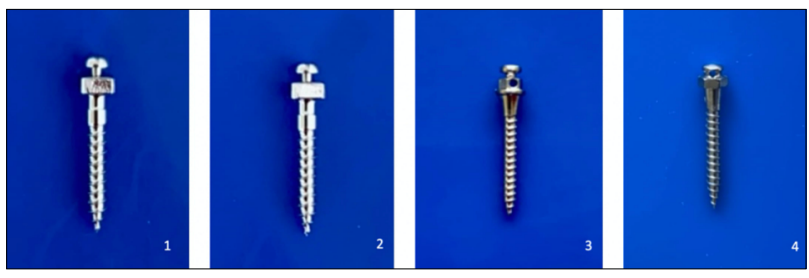

Fig. 1: Geometric configuration of the mini-screws used in the tests. 1: MPO Bomei Titanium; 2: MPO Bomei Stainless Steel; 3: MPO Morelli Titanium; 4: MPO Neodent Titanium. 
Table 1. Characteristics of the mini-screws used in the experimental tests.

\begin{tabular}{c|c|c|c|c|c|} 
Manufacturer & $\begin{array}{c}\text { External Diameter } \\
(\mathbf{m m})\end{array}$ & Length $\mathbf{( m m )}$ & Alloy & System & Pitch $(\mathbf{m m})$ \\
\hline Morelli & 1.5 & 10.0 & Ti 6Al-4V & Self-Drilling & 0.65 \\
\hline Neodent & 1.6 & 11.0 & Ti 6Al-4V & Self-Drilling & 0.73 \\
\hline Bomei & 2.0 & 12.0 & Ti 6Al-4V & Self-Drilling & 0.75 \\
\hline Bomei & 2.0 & 12.0 & Stainless Steel & Self-Drilling & 0.75 \\
\hline
\end{tabular}

procedure (Figure 2a, 2b, 2c). Positioners were fixed between the selected molars to guide the initiation of the process with the appropriate inclination.

The pig mandibles were fixed in a vice supported on a bench. A single experienced surgeon inserted the mini-screws at the mucogingival junction in the posterior region between the $1^{\text {st }}$ and $2^{\text {nd }}$ molars, into the external oblique line (buccal shelf), using the insertion tools provided by each manufacturer. Two insertion procedures were carried out:

- Direct insertion at 30 ${ }^{\circ}$ : The mini-screws were positioned at $30^{\circ}$ relative to the long tooth axis and inserted in this position up to the end of the thread or beginning of the transmucosal profile (Fig.3a). Ten direct insertion procedures were performed at $30^{\circ}$ for each type of screw tested.

- Indirect insertion at $60^{\circ}$ positioning, ending at $3^{\mathbf{0}}$ : This procedure begins by positioning the mini-screws initially at $60^{\circ}$ in relation to the long tooth axis (Fig. 3b). After inserting approximately $2 \mathrm{~mm}$, the mini-screws are gradually inclined to the $30^{\circ}$ position, while inserting up to the end of thread or beginning of the transmucosal profile, according to the extra-alveolar technique recommended by Chang? ${ }^{7}$. Thereby, there is a

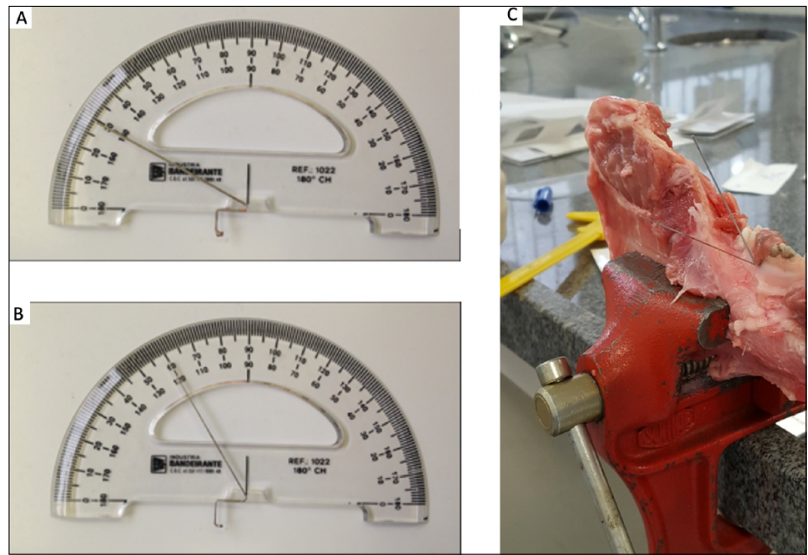

Fig. 2: Positioners made of 0.17 " $x$ 0.25" stainless steel wires a) $30^{\circ}$, b) $60^{\circ}$, c) in position between molars. gradual bending effect on the mini-screw during the insertion process. Ten indirect insertion procedures were performed at $60^{\circ}$ for each type of screw tested.

The mini-screws were then removed from the mandibles by the same surgeon using the same tool as for the insertions.

\section{Optical Microscopy and Scanning Electronic Microscopy (SEM)}

Mini-screw strain was analyzed using a CLS 100 Leica optical microscope at magnifications of 1.0, 1.6, 2.5 and $4.0 \mathrm{X}$, considering head, transmucosal profile, thread and tip.

Strain was then accurately analyzed using scanning electron microscopy of the samples which were mounted on aluminum bases with double-sided carbon tape, in an EVO model MA 10 (Zeiss, Germany) in the high vacuum range. Photomicrographs at 28x magnification of the head, transmucosal portion and thread portion of the miniscrews were used

\section{Statistical analysis}

Strain was evaluated only as present or absent, since any level of strain that occurred could compromise

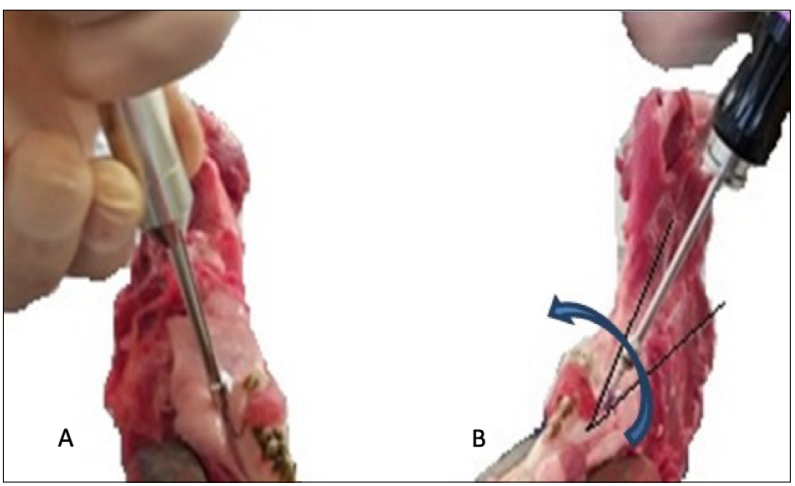

Fig. 3: Insertion of the mini-screws using a directly process $(A)$ and an indirectly process (B). 


\section{RESULTS}

Figs. 4 and 5 show the strain and fractures in the mini-screws evaluated by SEM microscopy. The steel mini-screws did not suffer deformations during the direct insertion process at $30^{\circ}$, showing the greater resistance in this type of fixation.

Taken as a whole, the number of strained titanium mini-screws was high among those subjected to direct insertion, and even higher in those subjected to indirect insertion. Statistically significant difference was found between percentages of strained and nonstrained groups. (Fig 6 and Table 2).

Evaluation of strain generated by direct insertion showed that the structural condition was better in stainless steel mini-screws than in titanium miniscrews (Table 3 ).

With Indirect insertion no statistically significant difference was found between the stainless steel and titanium mini-screws $(2.0 \times 12 \mathrm{~mm})$, which both showed some deformations.

Contrary to expectations, the longer and larger diameter mini-screws $(2.0 \times 12 \mathrm{~mm})$ suffered fewer alterations than those of shorter and larger diameters the quality of extra-alveolar anchorage. Each type of
mini-screw was compared to controls without strain
considering the regions analyzed. Deformed and
undeformed mini-screws were counted to evaluate
the level of structural resistance.
Score 0 (zero) was assigned to mini-screws which
remained intact and score 1 (one) for mini-screws
which suffered any strain or fracture. This procedure
was used because from a structural standpoint, any
level of strain could lead to early failure of the
mini-screw or change the stabilization conditions
expected in an extra-alveolar anchorage process.
Gold standard 2.0 x 12 mm stainless steel mini-
screws recommended in the Chang technique ${ }^{7}$ were
compared to titanium alloy mini-screws of the
same diameter and length, both made by the same
manufacturer (Bomei-Taiwan). Two other titanium
mini-screws manufactured by Morelli-Brazil (1.5
$\mathrm{x} 10$ mm) and Neodent-Brazil (1.6 $\mathrm{x} 11 \mathrm{~mm}$ ), which
were smaller in diameter and length, were also
evaluated.
The Kruskal-Wallis non-parametric test was applied. Fig. $4:$ Mini-Screws strained and unstrained under SEM
After confirming statistical differences, the Tamhane analysis.
post hoc test was used to reduce statistical errors
and to determine which pairs presented significant
statistical differences (p< 0.05 ). the quality of extra-alveolar anchorage. Each type of
mini-screw was compared to controls without strain
considering the regions analyzed. Deformed and
undeformed mini-screws were counted to evaluate
the level of structural resistance.
Score 0 (zero) was assigned to mini-screws which
remained intact and score 1 (one) for mini-screws
which suffered any strain or fracture. This procedure
was used because from a structural standpoint, any
level of strain could lead to early failure of the
mini-screw or change the stabilization conditions
expected in an extra-alveolar anchorage process.
Gold standard 2.0 x 12 mm stainless steel mini-
screws recommended in the Chang technique ${ }^{7}$ were
compared to titanium alloy mini-screws of the
same diameter and length, both made by the same
manufacturer (Bomei-Taiwan). Two other titanium
mini-screws manufactured by Morelli-Brazil (1.5
$\mathrm{x} 10$ mm) and Neodent-Brazil (1.6 $\mathrm{x} 11 \mathrm{~mm}$ ), which
were smaller in diameter and length, were also
evaluated.
The Kruskal-Wallis non-parametric test was applied. Fig. $4:$ Mini-Screws strained and unstrained under SEM
After confirming statistical differences, the Tamhane analysis.
post hoc test was used to reduce statistical errors
and to determine which pairs presented significant
statistical differences (p< 0.05 ). the quality of extra-alveolar anchorage. Each type of
mini-screw was compared to controls without strain
considering the regions analyzed. Deformed and
undeformed mini-screws were counted to evaluate
the level of structural resistance.
Score 0 (zero) was assigned to mini-screws which
remained intact and score 1 (one) for mini-screws
which suffered any strain or fracture. This procedure
was used because from a structural standpoint, any
level of strain could lead to early failure of the
mini-screw or change the stabilization conditions
expected in an extra-alveolar anchorage process.
Gold standard 2.0 x 12 mm stainless steel mini-
screws recommended in the Chang technique ${ }^{7}$ were
compared to titanium alloy mini-screws of the
same diameter and length, both made by the same
manufacturer (Bomei-Taiwan). Two other titanium
mini-screws manufactured by Morelli-Brazil (1.5
$\mathrm{x} 10$ mm) and Neodent-Brazil (1.6 $\mathrm{x} 11 \mathrm{~mm}$ ), which
were smaller in diameter and length, were also
evaluated.
The Kruskal-Wallis non-parametric test was applied. Fig. $4:$ Mini-Screws strained and unstrained under SEM
After confirming statistical differences, the Tamhane analysis.
post hoc test was used to reduce statistical errors
and to determine which pairs presented significant
statistical differences (p< 0.05 ). the quality of extra-alveolar anchorage. Each type of
mini-screw was compared to controls without strain
considering the regions analyzed. Deformed and
undeformed mini-screws were counted to evaluate
the level of structural resistance.
Score 0 (zero) was assigned to mini-screws which
remained intact and score 1 (one) for mini-screws
which suffered any strain or fracture. This procedure
was used because from a structural standpoint, any
level of strain could lead to early failure of the
mini-screw or change the stabilization conditions
expected in an extra-alveolar anchorage process.
Gold standard 2.0 x 12 mm stainless steel mini-
screws recommended in the Chang technique ${ }^{7}$ were
compared to titanium alloy mini-screws of the
same diameter and length, both made by the same
manufacturer (Bomei-Taiwan). Two other titanium
mini-screws manufactured by Morelli-Brazil (1.5
$\mathrm{x} 10$ mm) and Neodent-Brazil (1.6 $\mathrm{x} 11 \mathrm{~mm}$ ), which
were smaller in diameter and length, were also
evaluated.
The Kruskal-Wallis non-parametric test was applied. Fig. $4:$ Mini-Screws strained and unstrained under SEM
After confirming statistical differences, the Tamhane analysis.
post hoc test was used to reduce statistical errors
and to determine which pairs presented significant
statistical differences (p< 0.05 ). the quality of extra-alveolar anchorage. Each type of
mini-screw was compared to controls without strain
considering the regions analyzed. Deformed and
undeformed mini-screws were counted to evaluate
the level of structural resistance.
Score 0 (zero) was assigned to mini-screws which
remained intact and score 1 (one) for mini-screws
which suffered any strain or fracture. This procedure
was used because from a structural standpoint, any
level of strain could lead to early failure of the
mini-screw or change the stabilization conditions
expected in an extra-alveolar anchorage process.
Gold standard 2.0 x 12 mm stainless steel mini-
screws recommended in the Chang technique ${ }^{7}$ were
compared to titanium alloy mini-screws of the
same diameter and length, both made by the same
manufacturer (Bomei-Taiwan). Two other titanium
mini-screws manufactured by Morelli-Brazil (1.5
$\mathrm{x} 10$ mm) and Neodent-Brazil (1.6 $\mathrm{x} 11 \mathrm{~mm}$ ), which
were smaller in diameter and length, were also
evaluated.
The Kruskal-Wallis non-parametric test was applied. Fig. $4:$ Mini-Screws strained and unstrained under SEM
After confirming statistical differences, the Tamhane analysis.
post hoc test was used to reduce statistical errors
and to determine which pairs presented significant
statistical differences (p< 0.05 ). the quality of extra-alveolar anchorage. Each type of
mini-screw was compared to controls without strain
considering the regions analyzed. Deformed and
undeformed mini-screws were counted to evaluate
the level of structural resistance.
Score 0 (zero) was assigned to mini-screws which
remained intact and score 1 (one) for mini-screws
which suffered any strain or fracture. This procedure
was used because from a structural standpoint, any
level of strain could lead to early failure of the
mini-screw or change the stabilization conditions
expected in an extra-alveolar anchorage process.
Gold standard 2.0 x 12 mm stainless steel mini-
screws recommended in the Chang technique ${ }^{7}$ were
compared to titanium alloy mini-screws of the
same diameter and length, both made by the same
manufacturer (Bomei-Taiwan). Two other titanium
mini-screws manufactured by Morelli-Brazil (1.5
$\mathrm{x} 10$ mm) and Neodent-Brazil (1.6 $\mathrm{x} 11 \mathrm{~mm}$ ), which
were smaller in diameter and length, were also
evaluated.
The Kruskal-Wallis non-parametric test was applied. Fig. $4:$ Mini-Screws strained and unstrained under SEM
After confirming statistical differences, the Tamhane analysis.
post hoc test was used to reduce statistical errors
and to determine which pairs presented significant
statistical differences (p< 0.05 ). the quality of extra-alveolar anchorage. Each type of
mini-screw was compared to controls without strain
considering the regions analyzed. Deformed and
undeformed mini-screws were counted to evaluate
the level of structural resistance.
Score 0 (zero) was assigned to mini-screws which
remained intact and score 1 (one) for mini-screws
which suffered any strain or fracture. This procedure
was used because from a structural standpoint, any
level of strain could lead to early failure of the
mini-screw or change the stabilization conditions
expected in an extra-alveolar anchorage process.
Gold standard 2.0 x 12 mm stainless steel mini-
screws recommended in the Chang technique ${ }^{7}$ were
compared to titanium alloy mini-screws of the
same diameter and length, both made by the same
manufacturer (Bomei-Taiwan). Two other titanium
mini-screws manufactured by Morelli-Brazil (1.5
$\mathrm{x} 10$ mm) and Neodent-Brazil (1.6 $\mathrm{x} 11 \mathrm{~mm}$ ), which
were smaller in diameter and length, were also
evaluated.
The Kruskal-Wallis non-parametric test was applied. Fig. $4:$ Mini-Screws strained and unstrained under SEM
After confirming statistical differences, the Tamhane analysis.
post hoc test was used to reduce statistical errors
and to determine which pairs presented significant
statistical differences (p< 0.05 ). the quality of extra-alveolar anchorage. Each type of
mini-screw was compared to controls without strain
considering the regions analyzed. Deformed and
undeformed mini-screws were counted to evaluate
the level of structural resistance.
Score 0 (zero) was assigned to mini-screws which
remained intact and score 1 (one) for mini-screws
which suffered any strain or fracture. This procedure
was used because from a structural standpoint, any
level of strain could lead to early failure of the
mini-screw or change the stabilization conditions
expected in an extra-alveolar anchorage process.
Gold standard 2.0 x 12 mm stainless steel mini-
screws recommended in the Chang technique ${ }^{7}$ were
compared to titanium alloy mini-screws of the
same diameter and length, both made by the same
manufacturer (Bomei-Taiwan). Two other titanium
mini-screws manufactured by Morelli-Brazil (1.5
$\mathrm{x} 10$ mm) and Neodent-Brazil (1.6 $\mathrm{x} 11 \mathrm{~mm}$ ), which
were smaller in diameter and length, were also
evaluated.
The Kruskal-Wallis non-parametric test was applied. Fig. $4:$ Mini-Screws strained and unstrained under SEM
After confirming statistical differences, the Tamhane analysis.
post hoc test was used to reduce statistical errors
and to determine which pairs presented significant
statistical differences (p< 0.05 ). the quality of extra-alveolar anchorage. Each type of
mini-screw was compared to controls without strain
considering the regions analyzed. Deformed and
undeformed mini-screws were counted to evaluate
the level of structural resistance.
Score 0 (zero) was assigned to mini-screws which
remained intact and score 1 (one) for mini-screws
which suffered any strain or fracture. This procedure
was used because from a structural standpoint, any
level of strain could lead to early failure of the
mini-screw or change the stabilization conditions
expected in an extra-alveolar anchorage process.
Gold standard 2.0 x 12 mm stainless steel mini-
screws recommended in the Chang technique ${ }^{7}$ were
compared to titanium alloy mini-screws of the
same diameter and length, both made by the same
manufacturer (Bomei-Taiwan). Two other titanium
mini-screws manufactured by Morelli-Brazil (1.5
$\mathrm{x} 10$ mm) and Neodent-Brazil (1.6 $\mathrm{x} 11 \mathrm{~mm}$ ), which
were smaller in diameter and length, were also
evaluated.
The Kruskal-Wallis non-parametric test was applied. Fig. $4:$ Mini-Screws strained and unstrained under SEM
After confirming statistical differences, the Tamhane analysis.
post hoc test was used to reduce statistical errors
and to determine which pairs presented significant
statistical differences (p< 0.05 ). the quality of extra-alveolar anchorage. Each type of
mini-screw was compared to controls without strain
considering the regions analyzed. Deformed and
undeformed mini-screws were counted to evaluate
the level of structural resistance.
Score 0 (zero) was assigned to mini-screws which
remained intact and score 1 (one) for mini-screws
which suffered any strain or fracture. This procedure
was used because from a structural standpoint, any
level of strain could lead to early failure of the
mini-screw or change the stabilization conditions
expected in an extra-alveolar anchorage process.
Gold standard 2.0 x 12 mm stainless steel mini-
screws recommended in the Chang technique ${ }^{7}$ were
compared to titanium alloy mini-screws of the
same diameter and length, both made by the same
manufacturer (Bomei-Taiwan). Two other titanium
mini-screws manufactured by Morelli-Brazil (1.5
$\mathrm{x} 10$ mm) and Neodent-Brazil (1.6 $\mathrm{x} 11 \mathrm{~mm}$ ), which
were smaller in diameter and length, were also
evaluated.
The Kruskal-Wallis non-parametric test was applied. Fig. $4:$ Mini-Screws strained and unstrained under SEM
After confirming statistical differences, the Tamhane analysis.
post hoc test was used to reduce statistical errors
and to determine which pairs presented significant
statistical differences (p< 0.05 ). the quality of extra-alveolar anchorage. Each type of
mini-screw was compared to controls without strain
considering the regions analyzed. Deformed and
undeformed mini-screws were counted to evaluate
the level of structural resistance.
Score 0 (zero) was assigned to mini-screws which
remained intact and score 1 (one) for mini-screws
which suffered any strain or fracture. This procedure
was used because from a structural standpoint, any
level of strain could lead to early failure of the
mini-screw or change the stabilization conditions
expected in an extra-alveolar anchorage process.
Gold standard 2.0 x 12 mm stainless steel mini-
screws recommended in the Chang technique ${ }^{7}$ were
compared to titanium alloy mini-screws of the
same diameter and length, both made by the same
manufacturer (Bomei-Taiwan). Two other titanium
mini-screws manufactured by Morelli-Brazil (1.5
$\mathrm{x} 10$ mm) and Neodent-Brazil (1.6 $\mathrm{x} 11 \mathrm{~mm}$ ), which
were smaller in diameter and length, were also
evaluated.
The Kruskal-Wallis non-parametric test was applied. Fig. $4:$ Mini-Screws strained and unstrained under SEM
After confirming statistical differences, the Tamhane analysis.
post hoc test was used to reduce statistical errors
and to determine which pairs presented significant
statistical differences (p< 0.05 ). the quality of extra-alveolar anchorage. Each type of
mini-screw was compared to controls without strain
considering the regions analyzed. Deformed and
undeformed mini-screws were counted to evaluate
the level of structural resistance.
Score 0 (zero) was assigned to mini-screws which
remained intact and score 1 (one) for mini-screws
which suffered any strain or fracture. This procedure
was used because from a structural standpoint, any
level of strain could lead to early failure of the
mini-screw or change the stabilization conditions
expected in an extra-alveolar anchorage process.
Gold standard 2.0 x 12 mm stainless steel mini-
screws recommended in the Chang technique ${ }^{7}$ were
compared to titanium alloy mini-screws of the
same diameter and length, both made by the same
manufacturer (Bomei-Taiwan). Two other titanium
mini-screws manufactured by Morelli-Brazil (1.5
$\mathrm{x} 10$ mm) and Neodent-Brazil (1.6 $\mathrm{x} 11 \mathrm{~mm}$ ), which
were smaller in diameter and length, were also
evaluated.
The Kruskal-Wallis non-parametric test was applied. Fig. $4:$ Mini-Screws strained and unstrained under SEM
After confirming statistical differences, the Tamhane analysis.
post hoc test was used to reduce statistical errors
and to determine which pairs presented significant
statistical differences (p< 0.05 ). the quality of extra-alveolar anchorage. Each type of
mini-screw was compared to controls without strain
considering the regions analyzed. Deformed and
undeformed mini-screws were counted to evaluate
the level of structural resistance.
Score 0 (zero) was assigned to mini-screws which
remained intact and score 1 (one) for mini-screws
which suffered any strain or fracture. This procedure
was used because from a structural standpoint, any
level of strain could lead to early failure of the
mini-screw or change the stabilization conditions
expected in an extra-alveolar anchorage process.
Gold standard 2.0 x 12 mm stainless steel mini-
screws recommended in the Chang technique ${ }^{7}$ were
compared to titanium alloy mini-screws of the
same diameter and length, both made by the same
manufacturer (Bomei-Taiwan). Two other titanium
mini-screws manufactured by Morelli-Brazil (1.5
$\mathrm{x} 10$ mm) and Neodent-Brazil (1.6 $\mathrm{x} 11 \mathrm{~mm}$ ), which
were smaller in diameter and length, were also
evaluated.
The Kruskal-Wallis non-parametric test was applied. Fig. $4:$ Mini-Screws strained and unstrained under SEM
After confirming statistical differences, the Tamhane analysis.
post hoc test was used to reduce statistical errors
and to determine which pairs presented significant
statistical differences (p< 0.05 ). the quality of extra-alveolar anchorage. Each type of
mini-screw was compared to controls without strain
considering the regions analyzed. Deformed and
undeformed mini-screws were counted to evaluate
the level of structural resistance.
Score 0 (zero) was assigned to mini-screws which
remained intact and score 1 (one) for mini-screws
which suffered any strain or fracture. This procedure
was used because from a structural standpoint, any
level of strain could lead to early failure of the
mini-screw or change the stabilization conditions
expected in an extra-alveolar anchorage process.
Gold standard 2.0 x 12 mm stainless steel mini-
screws recommended in the Chang technique ${ }^{7}$ were
compared to titanium alloy mini-screws of the
same diameter and length, both made by the same
manufacturer (Bomei-Taiwan). Two other titanium
mini-screws manufactured by Morelli-Brazil (1.5
$\mathrm{x} 10$ mm) and Neodent-Brazil (1.6 $\mathrm{x} 11 \mathrm{~mm}$ ), which
were smaller in diameter and length, were also
evaluated.
The Kruskal-Wallis non-parametric test was applied. Fig. $4:$ Mini-Screws strained and unstrained under SEM
After confirming statistical differences, the Tamhane analysis.
post hoc test was used to reduce statistical errors
and to determine which pairs presented significant
statistical differences (p< 0.05 ). the quality of extra-alveolar anchorage. Each type of
mini-screw was compared to controls without strain
considering the regions analyzed. Deformed and
undeformed mini-screws were counted to evaluate
the level of structural resistance.
Score 0 (zero) was assigned to mini-screws which
remained intact and score 1 (one) for mini-screws
which suffered any strain or fracture. This procedure
was used because from a structural standpoint, any
level of strain could lead to early failure of the
mini-screw or change the stabilization conditions
expected in an extra-alveolar anchorage process.
Gold standard 2.0 x 12 mm stainless steel mini-
screws recommended in the Chang technique ${ }^{7}$ were
compared to titanium alloy mini-screws of the
same diameter and length, both made by the same
manufacturer (Bomei-Taiwan). Two other titanium
mini-screws manufactured by Morelli-Brazil (1.5
$\mathrm{x} 10$ mm) and Neodent-Brazil (1.6 $\mathrm{x} 11 \mathrm{~mm}$ ), which
were smaller in diameter and length, were also
evaluated.
The Kruskal-Wallis non-parametric test was applied. Fig. $4:$ Mini-Screws strained and unstrained under SEM
After confirming statistical differences, the Tamhane analysis.
post hoc test was used to reduce statistical errors
and to determine which pairs presented significant
statistical differences (p< 0.05 ). the quality of extra-alveolar anchorage. Each type of
mini-screw was compared to controls without strain
considering the regions analyzed. Deformed and
undeformed mini-screws were counted to evaluate
the level of structural resistance.
Score 0 (zero) was assigned to mini-screws which
remained intact and score 1 (one) for mini-screws
which suffered any strain or fracture. This procedure
was used because from a structural standpoint, any
level of strain could lead to early failure of the
mini-screw or change the stabilization conditions
expected in an extra-alveolar anchorage process.
Gold standard 2.0 x 12 mm stainless steel mini-
screws recommended in the Chang technique ${ }^{7}$ were
compared to titanium alloy mini-screws of the
same diameter and length, both made by the same
manufacturer (Bomei-Taiwan). Two other titanium
mini-screws manufactured by Morelli-Brazil (1.5
$\mathrm{x} 10$ mm) and Neodent-Brazil (1.6 $\mathrm{x} 11 \mathrm{~mm}$ ), which
were smaller in diameter and length, were also
evaluated.
The Kruskal-Wallis non-parametric test was applied. Fig. $4:$ Mini-Screws strained and unstrained under SEM
After confirming statistical differences, the Tamhane analysis.
post hoc test was used to reduce statistical errors
and to determine which pairs presented significant
statistical differences (p< 0.05 ). the quality of extra-alveolar anchorage. Each type of
mini-screw was compared to controls without strain
considering the regions analyzed. Deformed and
undeformed mini-screws were counted to evaluate
the level of structural resistance.
Score 0 (zero) was assigned to mini-screws which
remained intact and score 1 (one) for mini-screws
which suffered any strain or fracture. This procedure
was used because from a structural standpoint, any
level of strain could lead to early failure of the
mini-screw or change the stabilization conditions
expected in an extra-alveolar anchorage process.
Gold standard 2.0 x 12 mm stainless steel mini-
screws recommended in the Chang technique ${ }^{7}$ were
compared to titanium alloy mini-screws of the
same diameter and length, both made by the same
manufacturer (Bomei-Taiwan). Two other titanium
mini-screws manufactured by Morelli-Brazil (1.5
$\mathrm{x} 10$ mm) and Neodent-Brazil (1.6 $\mathrm{x} 11 \mathrm{~mm}$ ), which
were smaller in diameter and length, were also
evaluated.
The Kruskal-Wallis non-parametric test was applied. Fig. $4:$ Mini-Screws strained and unstrained under SEM
After confirming statistical differences, the Tamhane analysis.
post hoc test was used to reduce statistical errors
and to determine which pairs presented significant
statistical differences (p< 0.05 ). the quality of extra-alveolar anchorage. Each type of
mini-screw was compared to controls without strain
considering the regions analyzed. Deformed and
undeformed mini-screws were counted to evaluate
the level of structural resistance.
Score 0 (zero) was assigned to mini-screws which
remained intact and score 1 (one) for mini-screws
which suffered any strain or fracture. This procedure
was used because from a structural standpoint, any
level of strain could lead to early failure of the
mini-screw or change the stabilization conditions
expected in an extra-alveolar anchorage process.
Gold standard 2.0 x 12 mm stainless steel mini-
screws recommended in the Chang technique ${ }^{7}$ were
compared to titanium alloy mini-screws of the
same diameter and length, both made by the same
manufacturer (Bomei-Taiwan). Two other titanium
mini-screws manufactured by Morelli-Brazil (1.5
$\mathrm{x} 10$ mm) and Neodent-Brazil (1.6 $\mathrm{x} 11 \mathrm{~mm}$ ), which
were smaller in diameter and length, were also
evaluated.
The Kruskal-Wallis non-parametric test was applied. Fig. $4:$ Mini-Screws strained and unstrained under SEM
After confirming statistical differences, the Tamhane analysis.
post hoc test was used to reduce statistical errors
and to determine which pairs presented significant
statistical differences (p< 0.05 ). the quality of extra-alveolar anchorage. Each type of
mini-screw was compared to controls without strain
considering the regions analyzed. Deformed and
undeformed mini-screws were counted to evaluate
the level of structural resistance.
Score 0 (zero) was assigned to mini-screws which
remained intact and score 1 (one) for mini-screws
which suffered any strain or fracture. This procedure
was used because from a structural standpoint, any
level of strain could lead to early failure of the
mini-screw or change the stabilization conditions
expected in an extra-alveolar anchorage process.
Gold standard 2.0 x 12 mm stainless steel mini-
screws recommended in the Chang technique ${ }^{7}$ were
compared to titanium alloy mini-screws of the
same diameter and length, both made by the same
manufacturer (Bomei-Taiwan). Two other titanium
mini-screws manufactured by Morelli-Brazil (1.5
$\mathrm{x} 10$ mm) and Neodent-Brazil (1.6 $\mathrm{x} 11 \mathrm{~mm}$ ), which
were smaller in diameter and length, were also
evaluated.
The Kruskal-Wallis non-parametric test was applied. Fig. $4:$ Mini-Screws strained and unstrained under SEM
After confirming statistical differences, the Tamhane analysis.
post hoc test was used to reduce statistical errors
and to determine which pairs presented significant
statistical differences (p< 0.05 ). the quality of extra-alveolar anchorage. Each type of
mini-screw was compared to controls without strain
considering the regions analyzed. Deformed and
undeformed mini-screws were counted to evaluate
the level of structural resistance.
Score 0 (zero) was assigned to mini-screws which
remained intact and score 1 (one) for mini-screws
which suffered any strain or fracture. This procedure
was used because from a structural standpoint, any
level of strain could lead to early failure of the
mini-screw or change the stabilization conditions
expected in an extra-alveolar anchorage process.
Gold standard 2.0 x 12 mm stainless steel mini-
screws recommended in the Chang technique ${ }^{7}$ were
compared to titanium alloy mini-screws of the
same diameter and length, both made by the same
manufacturer (Bomei-Taiwan). Two other titanium
mini-screws manufactured by Morelli-Brazil (1.5
$\mathrm{x} 10$ mm) and Neodent-Brazil (1.6 $\mathrm{x} 11 \mathrm{~mm}$ ), which
were smaller in diameter and length, were also
evaluated.
The Kruskal-Wallis non-parametric test was applied. Fig. $4:$ Mini-Screws strained and unstrained under SEM
After confirming statistical differences, the Tamhane analysis.
post hoc test was used to reduce statistical errors
and to determine which pairs presented significant
statistical differences (p< 0.05 ). the quality of extra-alveolar anchorage. Each type of
mini-screw was compared to controls without strain
considering the regions analyzed. Deformed and
undeformed mini-screws were counted to evaluate
the level of structural resistance.
Score 0 (zero) was assigned to mini-screws which
remained intact and score 1 (one) for mini-screws
which suffered any strain or fracture. This procedure
was used because from a structural standpoint, any
level of strain could lead to early failure of the
mini-screw or change the stabilization conditions
expected in an extra-alveolar anchorage process.
Gold standard 2.0 x 12 mm stainless steel mini-
screws recommended in the Chang technique ${ }^{7}$ were
compared to titanium alloy mini-screws of the
same diameter and length, both made by the same
manufacturer (Bomei-Taiwan). Two other titanium
mini-screws manufactured by Morelli-Brazil (1.5
$\mathrm{x} 10$ mm) and Neodent-Brazil (1.6 $\mathrm{x} 11 \mathrm{~mm}$ ), which
were smaller in diameter and length, were also
evaluated.
The Kruskal-Wallis non-parametric test was applied. Fig. $4:$ Mini-Screws strained and unstrained under SEM
After confirming statistical differences, the Tamhane analysis.
post hoc test was used to reduce statistical errors
and to determine which pairs presented significant
statistical differences (p< 0.05 ). the quality of extra-alveolar anchorage. Each type of
mini-screw was compared to controls without strain
considering the regions analyzed. Deformed and
undeformed mini-screws were counted to evaluate
the level of structural resistance.
Score 0 (zero) was assigned to mini-screws which
remained intact and score 1 (one) for mini-screws
which suffered any strain or fracture. This procedure
was used because from a structural standpoint, any
level of strain could lead to early failure of the
mini-screw or change the stabilization conditions
expected in an extra-alveolar anchorage process.
Gold standard 2.0 x 12 mm stainless steel mini-
screws recommended in the Chang technique ${ }^{7}$ were
compared to titanium alloy mini-screws of the
same diameter and length, both made by the same
manufacturer (Bomei-Taiwan). Two other titanium
mini-screws manufactured by Morelli-Brazil (1.5
$\mathrm{x} 10$ mm) and Neodent-Brazil (1.6 $\mathrm{x} 11 \mathrm{~mm}$ ), which
were smaller in diameter and length, were also
evaluated.
The Kruskal-Wallis non-parametric test was applied. Fig. $4:$ Mini-Screws strained and unstrained under SEM
After confirming statistical differences, the Tamhane analysis.
post hoc test was used to reduce statistical errors
and to determine which pairs presented significant
statistical differences (p< 0.05 ). the quality of extra-alveolar anchorage. Each type of
mini-screw was compared to controls without strain
considering the regions analyzed. Deformed and
undeformed mini-screws were counted to evaluate
the level of structural resistance.
Score 0 (zero) was assigned to mini-screws which
remained intact and score 1 (one) for mini-screws
which suffered any strain or fracture. This procedure
was used because from a structural standpoint, any
level of strain could lead to early failure of the
mini-screw or change the stabilization conditions
expected in an extra-alveolar anchorage process.
Gold standard 2.0 x 12 mm stainless steel mini-
screws recommended in the Chang technique ${ }^{7}$ were
compared to titanium alloy mini-screws of the
same diameter and length, both made by the same
manufacturer (Bomei-Taiwan). Two other titanium
mini-screws manufactured by Morelli-Brazil (1.5
$\mathrm{x} 10$ mm) and Neodent-Brazil (1.6 $\mathrm{x} 11 \mathrm{~mm}$ ), which
were smaller in diameter and length, were also
evaluated.
The Kruskal-Wallis non-parametric test was applied. Fig. $4:$ Mini-Screws strained and unstrained under SEM
After confirming statistical differences, the Tamhane analysis.
post hoc test was used to reduce statistical errors
and to determine which pairs presented significant
statistical differences (p< 0.05 ). the quality of extra-alveolar anchorage. Each type of
mini-screw was compared to controls without strain
considering the regions analyzed. Deformed and
undeformed mini-screws were counted to evaluate
the level of structural resistance.
Score 0 (zero) was assigned to mini-screws which
remained intact and score 1 (one) for mini-screws
which suffered any strain or fracture. This procedure
was used because from a structural standpoint, any
level of strain could lead to early failure of the
mini-screw or change the stabilization conditions
expected in an extra-alveolar anchorage process.
Gold standard 2.0 x 12 mm stainless steel mini-
screws recommended in the Chang technique ${ }^{7}$ were
compared to titanium alloy mini-screws of the
same diameter and length, both made by the same
manufacturer (Bomei-Taiwan). Two other titanium
mini-screws manufactured by Morelli-Brazil (1.5
$\mathrm{x} 10$ mm) and Neodent-Brazil (1.6 $\mathrm{x} 11 \mathrm{~mm}$ ), which
were smaller in diameter and length, were also
evaluated.
The Kruskal-Wallis non-parametric test was applied. Fig. $4:$ Mini-Screws strained and unstrained under SEM
After confirming statistical differences, the Tamhane analysis.
post hoc test was used to reduce statistical errors
and to determine which pairs presented significant
statistical differences (p< 0.05 ). the quality of extra-alveolar anchorage. Each type of
mini-screw was compared to controls without strain
considering the regions analyzed. Deformed and
undeformed mini-screws were counted to evaluate
the level of structural resistance.
Score 0 (zero) was assigned to mini-screws which
remained intact and score 1 (one) for mini-screws
which suffered any strain or fracture. This procedure
was used because from a structural standpoint, any
level of strain could lead to early failure of the
mini-screw or change the stabilization conditions
expected in an extra-alveolar anchorage process.
Gold standard 2.0 x 12 mm stainless steel mini-
screws recommended in the Chang technique ${ }^{7}$ were
compared to titanium alloy mini-screws of the
same diameter and length, both made by the same
manufacturer (Bomei-Taiwan). Two other titanium
mini-screws manufactured by Morelli-Brazil (1.5
$\mathrm{x} 10$ mm) and Neodent-Brazil (1.6 $\mathrm{x} 11 \mathrm{~mm}$ ), which
were smaller in diameter and length, were also
evaluated.
The Kruskal-Wallis non-parametric test was applied. Fig. $4:$ Mini-Screws strained and unstrained under SEM
After confirming statistical differences, the Tamhane analysis.
post hoc test was used to reduce statistical errors
and to determine which pairs presented significant
statistical differences (p< 0.05 ). the quality of extra-alveolar anchorage. Each type of
mini-screw was compared to controls without strain
considering the regions analyzed. Deformed and
undeformed mini-screws were counted to evaluate
the level of structural resistance.
Score 0 (zero) was assigned to mini-screws which
remained intact and score 1 (one) for mini-screws
which suffered any strain or fracture. This procedure
was used because from a structural standpoint, any
level of strain could lead to early failure of the
mini-screw or change the stabilization conditions
expected in an extra-alveolar anchorage process.
Gold standard 2.0 x 12 mm stainless steel mini-
screws recommended in the Chang technique ${ }^{7}$ were
compared to titanium alloy mini-screws of the
same diameter and length, both made by the same
manufacturer (Bomei-Taiwan). Two other titanium
mini-screws manufactured by Morelli-Brazil (1.5
$\mathrm{x} 10$ mm) and Neodent-Brazil (1.6 $\mathrm{x} 11 \mathrm{~mm}$ ), which
were smaller in diameter and length, were also
evaluated.
The Kruskal-Wallis non-parametric test was applied. Fig. $4:$ Mini-Screws strained and unstrained under SEM
After confirming statistical differences, the Tamhane analysis.
post hoc test was used to reduce statistical errors
and to determine which pairs presented significant
statistical differences (p< 0.05 ).

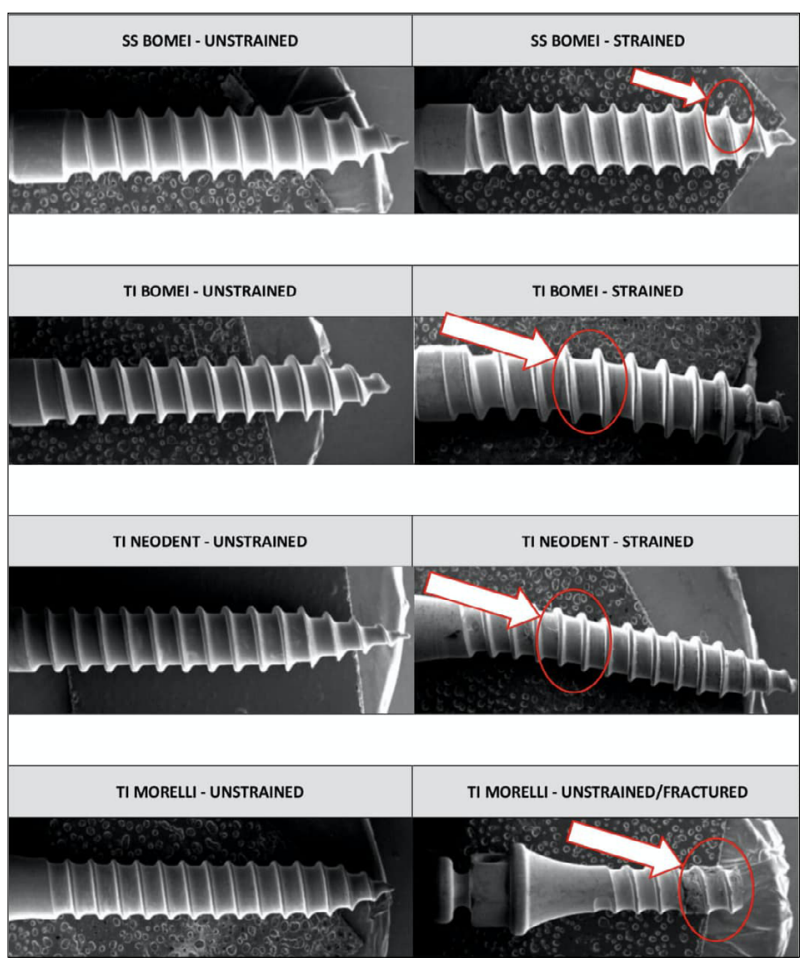

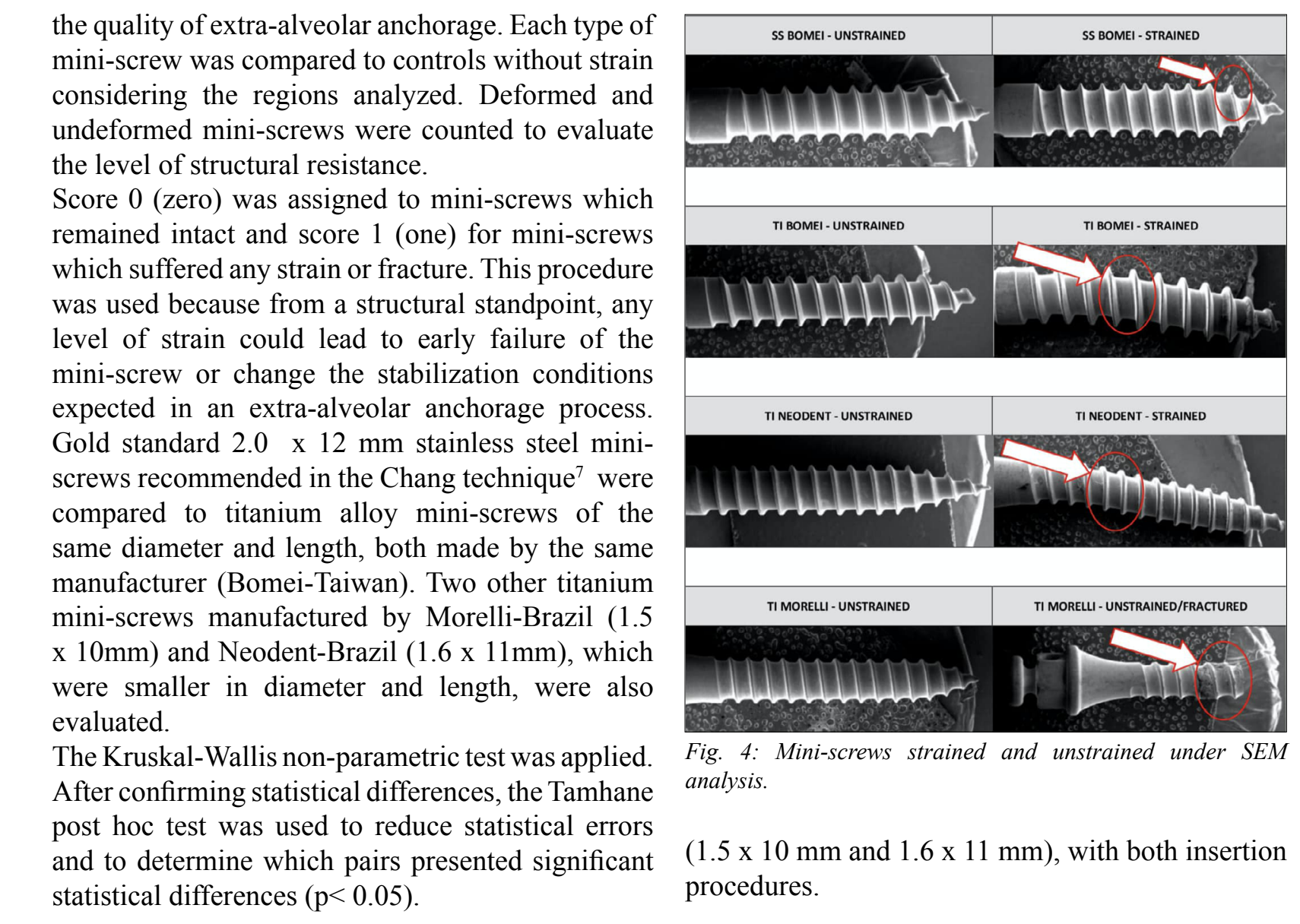

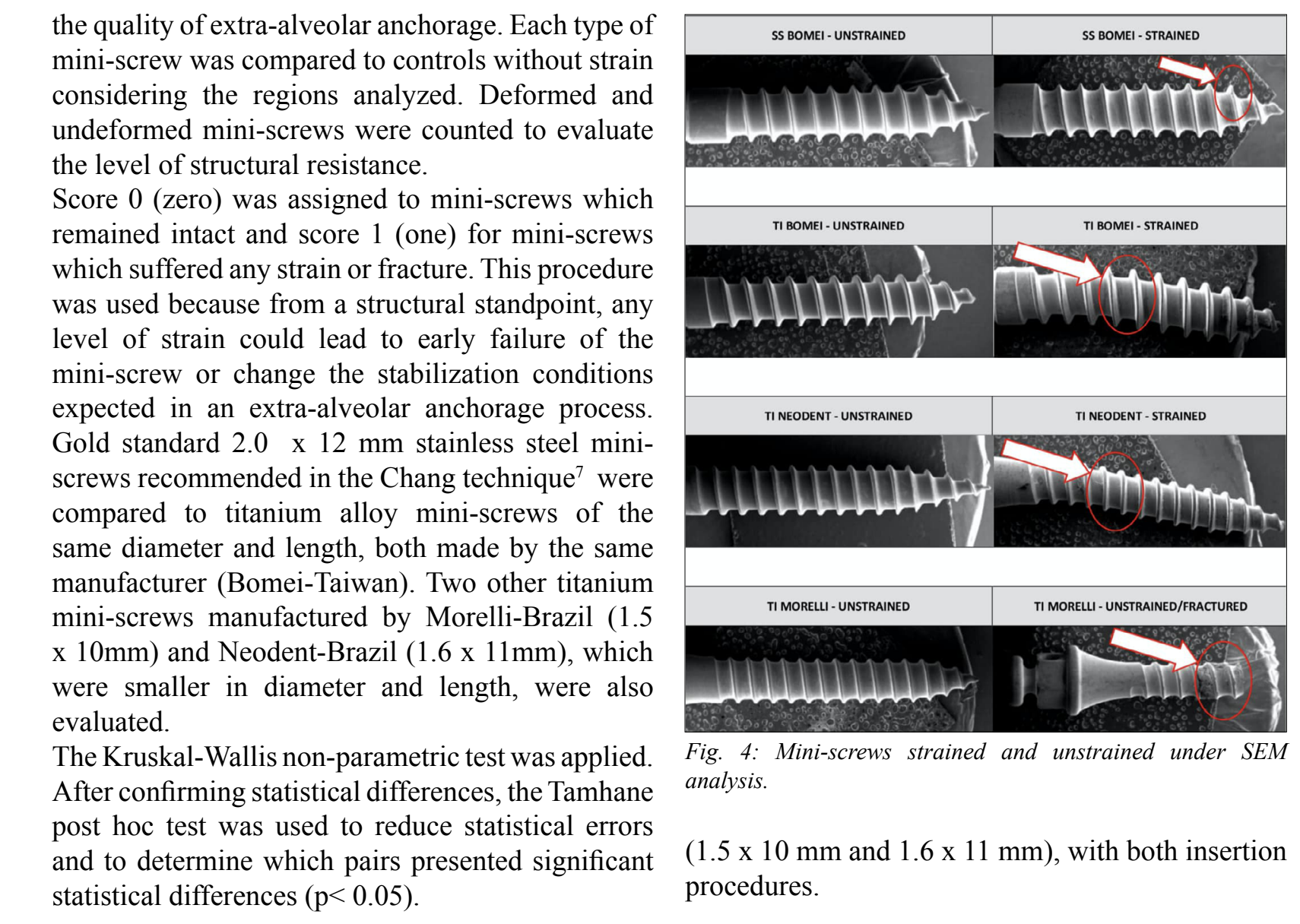
the quality of extra-alveolar anchorage. Each type of
mini-screw was compared to controls without strain
considering the regions analyzed. Deformed and
undeformed mini-screws were counted to evaluate
the level of structural resistance.
Score 0 (zero) was assigned to mini-screws which
remained intact and score 1 (one) for mini-screws
which suffered any strain or fracture. This procedure
was used because from a structural standpoint, any
level of strain could lead to early failure of the
mini-screw or change the stabilization conditions
expected in an extra-alveolar anchorage process.
Gold standard 2.0 x 12 mm stainless steel mini-
screws recommended in the Chang technique ${ }^{7}$ were
compared to titanium alloy mini-screws of the
same diameter and length, both made by the same
manufacturer (Bomei-Taiwan). Two other titanium
mini-screws manufactured by Morelli-Brazil (1.5
$\mathrm{x} 10$ mm) and Neodent-Brazil (1.6 $\mathrm{x} 11 \mathrm{~mm}$ ), which
were smaller in diameter and length, were also
evaluated.
The Kruskal-Wallis non-parametric test was applied. Fig. $4:$ Mini-Screws strained and unstrained under SEM
After confirming statistical differences, the Tamhane analysis.
post hoc test was used to reduce statistical errors
and to determine which pairs presented significant
statistical differences (p< 0.05 ). the quality of extra-alveolar anchorage. Each type of
mini-screw was compared to controls without strain
considering the regions analyzed. Deformed and
undeformed mini-screws were counted to evaluate
the level of structural resistance.
Score 0 (zero) was assigned to mini-screws which
remained intact and score 1 (one) for mini-screws
which suffered any strain or fracture. This procedure
was used because from a structural standpoint, any
level of strain could lead to early failure of the
mini-screw or change the stabilization conditions
expected in an extra-alveolar anchorage process.
Gold standard 2.0 x 12 mm stainless steel mini-
screws recommended in the Chang technique ${ }^{7}$ were
compared to titanium alloy mini-screws of the
same diameter and length, both made by the same
manufacturer (Bomei-Taiwan). Two other titanium
mini-screws manufactured by Morelli-Brazil (1.5
$\mathrm{x} 10$ mm) and Neodent-Brazil (1.6 $\mathrm{x} 11 \mathrm{~mm}$ ), which
were smaller in diameter and length, were also
evaluated.
The Kruskal-Wallis non-parametric test was applied. Fig. $4:$ Mini-Screws strained and unstrained under SEM
After confirming statistical differences, the Tamhane analysis.
post hoc test was used to reduce statistical errors
and to determine which pairs presented significant
statistical differences (p< 0.05 ).

\section{DISCUSSION}

The aim of this study was to evaluate the performance of Morelli/Brazil mini-screws (Ti $1.5 \times 10 \mathrm{~mm}$ ) and Neodent/Brazil mini-screws (Ti $1.6 \mathrm{x} 11 \mathrm{~mm}$ ) in extra-alveolar insertion and to test and compare the

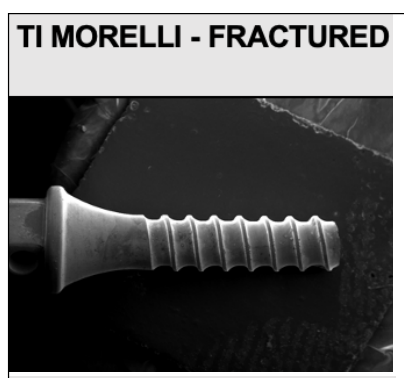

TI NEODENT - STRAINED

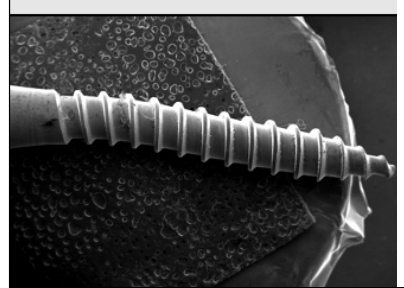

Fig. 5: SEM microscopy of mini-screws inserted by direct technique.

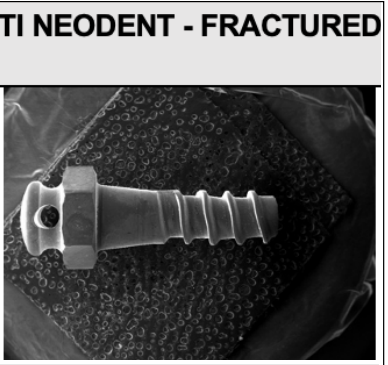

TI BOMEI - FRACTURED

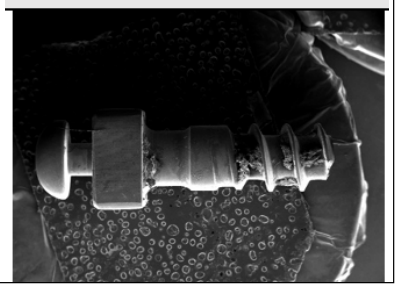




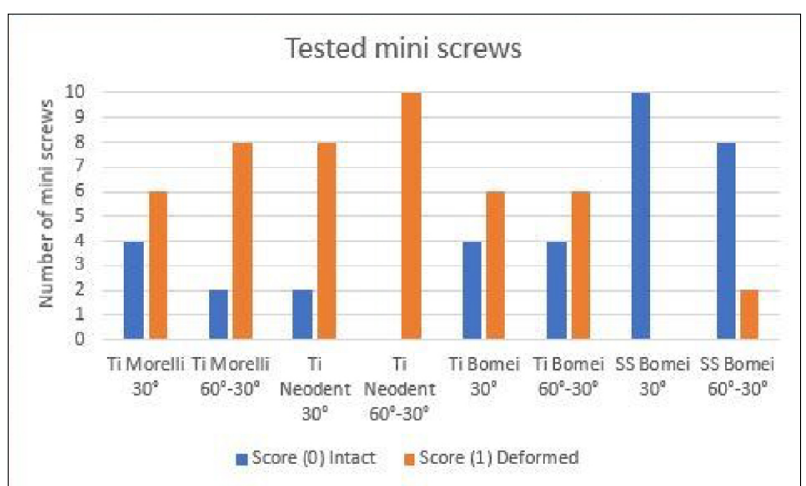

Fig. 6: a) Amounts of strained and strained mini-screw after direct and indirect insertion.

structural resistance of two selected OBS Bomei/ Taiwan mini-screws, Ti $2.0 \times 12 \mathrm{~mm}$ and SS 2.0 $\mathrm{x} 12 \mathrm{~mm}$, the latter recommended by Chris Chang ${ }^{7}$, who was a precursor of the extra-alveolar insertion technique.

Pig mandibles used as a model for extra-alveolar skeletal anchorage were chosen because their bone density and metabolism are similar to those of human bone ${ }^{10}$.

We propose to evaluate the outcome of direct and indirect insertion with different mini-screws, to determine how suitable they are for this procedure and to reduce the risks of early failure. When extraalveolar anchorage is used in orthodontic treatment, several factors should be considered for the choice of the mini-screws, such as the bone thickness of the insertion site, the alloy, the diameter and length and the angle of insertion, and whether to use a direct or indirect process ${ }^{11-14}$.

The insertion sites in thick cortical bone, requires high torques for insertion and removal ${ }^{15}$. Appropriate bone density and thickness are critical for the success of the mini-screws ${ }^{16-18}$ to ensure the greater stability $^{19-21}$ and higher torques ${ }^{22}$.

Since torque magnitude, for insertion and removal of orthodontic mini-screws, depends on cortical bone thickness ${ }^{23,24}$, areas with greater bone thickness should be selected in order to achieve better stability $^{25}$. However, torque should not be excessive, since higher levels may cause bone tissue damage and necrosis, as well as fractures or strains in the mini-screws, thus compromising stability.

Among the longest and largerst diameter miniscrews, only $35 \%$ suffered alterations, while $80 \%$ of the shorter and smaller diameter screws showed deformation or fracture. Awareness of the insertion site is therefore important, since bone density and

\begin{tabular}{l}
$\begin{array}{l}\text { Table 2. Statistics for direct and indirect } \\
\text { insertion using Kruskal-Wallis Test. }\end{array}$ \\
\begin{tabular}{|c|c|c|}
\hline \multicolumn{1}{|c|}{$\begin{array}{c}\text { Statistical } \\
\text { parameter }\end{array}$} & \multicolumn{2}{|c|}{$\begin{array}{c}\text { Deformed } \\
\text { condition }\end{array}$} \\
\hline Chi-square & $\begin{array}{c}\text { Direct } \\
\text { Insertion }\end{array}$ & $\begin{array}{c}\text { Indirect } \\
\text { Insertion }\end{array}$ \\
\hline Degrees of Freedom & 14.04 & 15.00 \\
\hline $\begin{array}{l}\text { Significance Level } \\
(p<0.05)\end{array}$ & 3 & 3 \\
\hline
\end{tabular} \\
\hline
\end{tabular}

\section{Table 3. Comparative analysis of direct and indirect insertion using the post hoc Tamhane} test.

\section{Direct Insertion}

Mini Screws Compared

$\begin{gathered}\text { Significance } \\ (\boldsymbol{p}<0.05)\end{gathered}$
0.030
0.001
0.030

Bomei Steel - Morelli Ti

Bomei Steel - Neodent Ti

0.030

Indirect Insertion

Mini Screws Compared

Significance $(p<0.05)$

Bomei Steel - Morelli Ti

0.031

Bomei Steel - Neodent Ti

0.001

Bomei Steel - Bomei Ti

0.372

thickness are essential factors for instability and increase of torques.

The mechanical properties of materials are also essential for greater safety against failure of miniscrews $^{26,27}$. The chosen material must have sufficient mechanical strength to withstand stresses due to the effect of torsion and bending on the threads during placement and clinical removal, without permanent strain $^{28,5}$. Most orthodontic mini-screws for anchorage are manufactured from titanium alloys or stainless steel. They both meet the biomechanical requirements for anchorage ${ }^{29}$. However, stainless steel mini-screws have proven to be more resistant to failure than titanium ${ }^{30,31}$.

In thicker corticals, it was observed that insertion and removal torque are greater for titanium miniscrews than for stainless steel mini-screws. Fracture resistance, measured by maximum fracture torque, was higher in stainless steel mini-screws than in titanium mini-screws, showing that the insertion process is safer with the use of stainless steel mini-screws ${ }^{4}$. Stainless steel has better mechanical properties considering the effects of bending, because of its greater ductility. The torsional resistance of stainless steel provides greater 
sensitivity to the professional during insertion, mini-screws do not provide tactile response during insertion, so it is difficult for professionals to notice when the rupture is about to occur ${ }^{29}$. Thus, ductility is a very important property because in extra-alveolar anchorage, the mini-screws will almost always require tilt adjustments, even when the insertions are made directly at $30^{\circ}$, as shown in this study.

The comparison of mini-screws of the same diameter and length showed that the mini-screws made of stainless steel alloy performed better than the mini-screws made of titanium alloy for the direct insertions at $30^{\circ}$. For indirect insertion, from $60^{\circ}$ to $30^{\circ}$, deformations were observed in both alloys, demonstrating that the angular changes interfere in the structure of both titanium and stainless steel mini-screws. In the evaluation of the performance of mini-screws with smaller diameters and lengths, in both insertions procedures the deformations were large, being greater in the $60^{\circ}$ to $30^{\circ}$ insertions, also demonstrating that changes of angulation should be avoided if possible, thereby improving performance and decreasing failure rates.

Regarding the diameter and length of the miniscrews, they are factors that also affect the stability. The larger the mini-screws, the greater the insertion thereby minimizing the risk of fracture. Titanium

and pulling forces ${ }^{32,33}$. Greater lengths offer greater resistance to the pullout test, which presupposes greater primary stability ${ }^{34}$. Greater diameters influence the insertion torque ${ }^{35}$. The mini-screws with the largest diameter show greater strength ${ }^{36-38}$. Therefore, an increase in mini-screw diameter can efficiently reinforce the initial stability, and the insertion torque increases with the increasing diameter and length ${ }^{39,40}$.

The results of our study are in accordance with the literature, because it was observed that the different diameters $(1.5 ; 1.6 ; 2.0 \mathrm{~mm})$ and lengths $(10 ; 11 ; 12$ $\mathrm{mm}$ ) correlate with performance, evaluated in terms of number of strained mini-screws.

The results of this study could help orthodontists in choosing mini-screws for extra-alveolar anchoring, which can be performed using direct $\left(30^{\circ}\right)$ or indirect insertion (starting at $60^{\circ}$ and ending gradually at $30^{\circ}$, with continuous tightening and inclination of the mini-screws).

It is advisable to use mini-screws for extra-alveolar anchorage, but attention should be given to bone thickness, the diameter and length of the miniscrews, the type of alloy and its ability to flex, and especially to changes in the angle during insertions, in order to reduce failure rates and ensure that the best choice is made.

\section{FUNDING}

None

The authors thank the Taiwanese manufacturer BOMEI Co. Ltd, in particular Steven Pan, who kindly provided the miniscrews and CPBIO Laboratory of the School of Dentistry of the Federal University of Uberlândia and the Multiuser Laboratory of Scanning Electronic Microscopy of the School of Chemical Engineering of the Federal University of Uberlândia for SEM analyses. We also thank the Mechanical Projects Lab and CINTESP.Br.

\section{DECLARATION OF CONFLICTING INTERESTS}

The authors declared no potential conflicts of interest with respect to the research, authorship, and/or publication of this article.

\section{REFERENCES}

1. Nascimento MHA, Araújo TM, Bezerra F. Microparafuso ortodôntico: instalação e protocolo de higieneSi-implantar. Ver Clin Orto Dental Press 2006;5:24-43.

2. Chung K, Kim SH, Kook Y. C-orthodontic microimplant for distalization of mandibular dentition in Class III correction. Angle Orthod 2005 2005;75:119-128.

3. Yamaguchi M, Inami T, Ito K, Kasai K, Tanimoto Y. Mini-

\section{CORRESPONDENCE}

Dr. Carlos Alberto de Morais Vieira

Federal University of Uberlandia - Umuarama Campus, Dentistry School

Rua Republica do Piratini, 1230

Uberlândia, Minas Gerais, Brasil, 38405-266

carlosamvieira@hotmail.com implants in the anchorage armamentarium: new paradigms in the orthodontics. Int J Biomater 2012;2012:394121.

4. Dalvi, ÂC. Implantes Ortodônticos de aço inoxidável. PhD (thesis). Rio de Janeiro, Instituto Militar de Engenharia, 2014. URL: http://www.ime.eb.mil.br/arquivos/teses/se4/ cm/Tese_Angela_Cardoso_Dalvi.pdf

5. Sana S, Manjunath G. Mini-Implant Materials: An 
Overview. IOSR J Dental Science and Medical Science 2013;7:15-20. DOI:10.9790/0853-0721520

6. Park, HS: O Uso de Microimplantes na Ortodontia. In: Nanda R, Kapila S: Terapias Atuais em Ortodontia. Rio de Janeiro, Brazil: Elsevier, 2011:291-300.

7. Chang CW, Eugene R. Stability of mini-screws on buccal shelves: a retrospective study of 1680 mini-screw insertions by the same orthodontist. Int $\mathrm{J}$ Orthod Implant 2013;30:76-78. URL: http://iaoi.pro/asset/files/ijoi_30_ pdf_article/076_078_new.pdf

8. Liou EJ, Pai BC, Lin JC. Do miniscrews remain stationary under orthodontic forces? Am J Orthod Dentofacial Orthop 2004;126:42-47.

9. Kravitz ND, Kusnoto B. Risks and complications of orthodontic miniscrews. Am J Orthod Dentofacial Orthop 2007;131:43-51.

10. Trento, CL. Densitometria óssea em mandíbula de suínos submetidos a enxerto ósseo autógeno, homógeno e heterógeno. PhD (thesis). Araçatuba, Faculdade de Odontologia, Universidade Estadual Paulista Júlio de Mesquita Filho, 2006. URL: https://repositorio.unesp. br/bitstream/handle/11449/102344/trento_cl_dr_araca. pdf;jsessionid=A3D6BC090D5FE6B1D2F2C $02748532 \mathrm{~A} 8$ 7? sequence $=1$

11. Consolaro A, Sant'ana E, Francischone-Jr CE, Consolaro MFM; Barbosa BA. Mini-implantes: pontos consensuais e questionamentos sobre o seu uso clinic.Dental Press Ortodon Ortop Facial 2008;13:20-27.

12. Fabre AF. Compêndio de Mini-Implantes Ortodônticos Parte I. Arch Health Invest 2014;3:46-56.

13. Janson M, Sant'Ana E, Vasconcelos W. Ancoragem esquelética com miniimplantes: incorporação rotineira da técnica na prática ortodôntica. Rev Clín Ortodon Dental Press 2006;5:85-100

14. Park HS, Jeong SH, Kwon OW. Factors affecting the clinical success of screw implants used as orthodontic anchorage. Am J Orthod Dentofacial Orthop 20061;130:18-25.

15. Fernandes DJ, Elias CN, Ruellas ACO. Influence of screw length and bone thickness on the stability of temporary implants. Materials (Basel) 2015;8:6558-6569.

16. Manni A, Cozzani M, Tamborrino F, De Rinaldis S, Menini A. Factors influencing the stability of miniscrews. A retrospective study on 300 miniscrews. Eur J Orthod 2011;33:388-395.

17. Moon CH, Lee DG, Lee HS, Im JS, Baek SH. Factors associated with the success rate of orthodontic miniscrews placed in the upper and lower posterior buccal region. Angle Orthod 2008;78:101-106.

18. Woods PW, Buschang PH, Owens SE, Rossouw PE, Opperman LA. The effect of force, timing, and location on bone-to-implant contact of miniscrew implants. Eur J Orthod 2009;31:232-240.

19. Brettin BT, Grosland NM, Qian F, Southard KA, Stuntz TD, Morgan TA, Marshall SD, Southard TE. Bicortical vs monocortical orthodontic skeletal anchorage. Am J Orthod Dentofacial Orthop 2008;134:625-635.

20. Cho YM, Cha JY, Hwang CJ. The effect of rotation moment on the stability of immediately loaded orthodontic miniscrews: a pilot study. Eur J Orthod 2010;32:614-619.

21. Yano S, Motoyoshi M, Uemura M, Ono A, Shimizu N. Tapered orthodontic miniscrews induce bone-screw cohesion following immediate loading. Eur $\mathrm{J}$ Orthod 2006;28:541-546.

22. Ballard D, Darendeliler A, Vickers D (2011). Orthodontics \& Mini screws. Australian Society of Orthodontists and University of Sydney. URL: https://www.aso.org.au/ sites/default/files/uploaded-content/field_f_content_file/ orthodontics_and_mini-screws.pdf]

23. Pithon MM, Nojima LI. Avaliação da estabilidade primária de mini-implantes ortodônticos em diferentes regiões da maxila e mandíbula de porcos. Innov Implant J 2007;2:58-63.

24. Pithon MM, Nojima LI. Torque de inserção e remoção de mini-implantes ortodônticos em diferentes espessuras de cortical. Innov Implant J 2009:37-41.

25. Davi LR, Golin AL, Bernardes SR, Araújo CA, Neves FD. In vitro integrity of implant external hexagon after application of surgical placement torque simulating implant locking. Brazilian Oral Research 2008;22:125-131.

26. Galeotti A, Uomo R, Spagnuolo G, Paduano S, Cimino $\mathrm{R}$, Valletta R, D'Antò V. Effect of $\mathrm{pH}$ on in vitro biocompatibility of orthodontic miniscrew implants. Prog Orthod 2013;14:15.

27. Knutson KJ, Berzins DW. Corrosion of orthodontic temporary anchorage devices. Eur J Orthod 2013;35:500506.

28. Motoyoshi M, Hirabayashi M, Uemura M, Shimizu N. Recommended placement torque when tightening an orthodontic mini-implant. Clin Oral Implants Res 2006;17:109-114.

29. Yao CC, Chang HH, Chang JZ, Lai HH, Lu SC, Chen YJ. Revisiting the stability of mini-implants used for orthodontic anchorage. J Formos Med Assoc 2015;114:1122-1128.

30. Brown RN, Sexton BE, Gabriel Chu TM, Katona TR, Stewart KT, Kyung HM, Liu SS. Comparison of stainless steel and titanium alloy orthodontic miniscrew implants: a mechanical and histologic analysis. Am J Orthod Dentofacial Orthop 2014;145:496-504.

31. Carano A, Lonardo P, Velo S, Incorvati C. Mechanical properties of three different commercially available miniscrews for skeletal anchorage. Prog Orthod 2005;6:8297.

32. Migliorati M, Signori A, Silvestrini-Biavati A. Temporary anchorage device stability: an evaluation of thread shape factor. Eur J Orthod 2012;34:582-586.

33. Shah AH, Behrents RG, Kim KB, Kyung HM, Buschang $\mathrm{PH}$. Effects of screw and host factors on insertion torque and pullout strength. Angle Orthod 2012;82:603-610.

34. Gouvêa CCM. Avaliação da resistência ao arrancamento de mini- implantes ortodônticos: estudo laboratorial. MSc (dissertation). Araçatuba, Faculdade de Odontologia, Universidade Estadual Paulista Júlio de Mesquita Filho, 2011. URL: https://repositorio.unesp.br/ handle/11449/95786

35. Holm L, Cunningham SJ, Petrie A, Cousley RR. An in vitro study of factors affecting the primary stability of orthodontic mini-implants. Angle Orthod 2012 Nov;82:1022-1028.

36. Casaglia A, Dominici F, Pachì F, Turlà R, Cerroni L. Morphological observations and fractological considerations on orthodontics miniscrews. Minerva Stomatol 2010;59:465-476.

37. Jolley $\mathrm{TH}$, Chung $\mathrm{CH}$. Peak torque values at fracture of orthodontic miniscrews. J Clin Orthod 2007;41:326-328. 
38. Squeff LR, Simonson MBD, Elias CN, Nojima LI. Caracterização de mini-implantes utilizados na ancoragem ortodôntica. Rev Dent Press Ortodon Ortop Facial 2008;13:49-56.

39. Gracco A, Cirignaco A, Cozzani M, Boccaccio A, Pappalettere C, Vitale G. Numerical/experimental analysis of the stress field around miniscrews for orthodontic anchorage. Eur J Orthod 2009;31:12-20.

40. Lim SA, Cha JY, Hwang CJ. Insertion torque of orthodontic miniscrews according to changes in shape, diameter and length. Angle Orthod 2008;78:234-240. 